\title{
Literatura e música: união indissolúvel
}

\author{
Solange Ribeiro de Oliveira \\ Universidade Federal de Minas Gerais (UFMG), Brasil
}

DOI: https://doi.org/10.31492/2184-2043.RILP2020.37/pp.93-114

\begin{abstract}
Resumo
Como parte da Melopoética_disciplina voltada para o estudo de diferentes formas de relação entre Literatura e Música_o ensaio discute teorias e tipologias propostas por críticos como Steven Paul Scher, Werner Wolf, Paul Zumthor, Susanne Langer, Luis Tatit e Claus Clüver, entre outros. A partir de três eixos classificatórios_Música na Literatura, Literatura na Música, Literatura e Música_estudam-se várias possibilidades de relação entre as duas artes. A título de complementação, acrescentam-se análises de criações musicais brasileiras e europeias, selecionadas como ilustrativas dos temas focalizados. Reconhecendo a existência de aspectos significativos da Melopoética ainda por explorar, o texto se encerra com a sugestão de temas especialmente convidativos para pesquisas futuras, tais como a gênese da intermidialidade, funções das relações intermidiáticas, a figura do autor /compositor ou do leitor /ouvinte e a compilação de um dicionário de relações músico-literárias.
\end{abstract}

Palavras-chave: melopoética; teorias sobre as relações entre a música e a literatura; a tipologia of relações musico-literárias; composições brasileiras e europeias; temas para pesquisas futuras.

\begin{abstract}
As part of Melopoetics_defined as the study of different forms of relations between Literature and Music_the essay discusses theories and typologies put forth by critics like Steven Paul Scher, Werner Wolf, Paul Zumthor, Susanne Langer, Luis Tatit and Claus Clüver, among others. Starting from three classificatory axes Music in Literature, Literature in Music, Literature and Music_a number of possible relations between the two arts are analyzed. By way of complementation, the text considers certain Brazilian and European musical creations, selected as illustrative of the themes dealt with. Realizing the existence of significant aspects of Melopoetics still unexplored, the article ends up with a suggestion of themes especially instigating for future research, such as the genesis of intermediality, functions of intermediatic relations, the figure of the composer/ author and of the listener/reader and the compilation of a dictionary of musico-literary relations.
\end{abstract}

Keywords: Melopoetics; theories of musico-literary relations; a typology of musico-literary relations; Brazilian and European compositions; themes for future research.

\section{Introdução}

A união entre Literatura e Música, gêmeas nascidas da própria fala humana, perde-se nos albores da pré-história. Inseparáveis, teriam dado voz à expressão das paixões e das experiências insondáveis da alma. Em cantos tribais, lamentações coletivas, ou verbalizações pré-linguísticas, geraram mantras, preces, expressões indistintas de vivências comuns. Lentamente, ao fluir dos séculos, conforme a natureza do material acústico explorado, acabaram por bifurcar-se entre Poesia e Música. Entretanto, filhas do som e do tempo virtual, dotadas ambas de atributos como altura, duração, intensidade, timbre e ritmo, Literatura e Música não deixaram de ser irmãs. Na música ocidental, remontando à antiga poesia lírica, sua intrínseca afinidade possibilitou a criação de oratórios, cantatas, madrigais, 
coros, baladas, missas cantadas, a masque inglesa, passando pelo Singspiel alemão e a ópera até criações contemporâneas, como na poesia sonora e na música concreta. Inscrevem-se nessa história como personagens ilustres, a canção e suas variantes históricas como o lied.

Nenhuma tipologia lograria esgotar o vastíssimo campo de relações envolvidas nessas configurações. Entretanto, as tipologias mostram-se úteis como um primeiro passo para o mapeamento e a análise de semelhanças e diferenças entre os fenômenos músico-literários. Nesse sentido, destaco a proposta de Steven Paul Scher. Em sucessivas publicações (1968, 1970 e 1982), mostra-se referência indispensável para a Melopoética_nomenclatura proposta pelo crítico para o estudo das relações entre Literatura e Música. Para a abordagem dessa "disciplina indisciplinada", Scher propõe três grandes áreas:

-Literatura na Música;

-Literatura $e$ Música;

-Música na Literatura.

O último item, por sua vez, subdivide-se em três categorias: Música de Palavras, Música Verbal e Estruturas Musicais na Literatura.

\section{Literatura na Música}

Valendo-me desse esquema, começo por considerar o tipo de relação intitulado Literatura na Música. Nesse item Scher situa a chamada Música Programática, inspirada numa ideia extramusical e não raro apoiada num folheto ou "programa" escrito. Para orientar a interpretação do ouvinte, o programa narra uma história, descreve uma paisagem ou evoca personagens de narrativas conhecidas. Em formas variáveis, esse tipo de composição tem ancestrais veneráveis, encontrados pelo menos a partir do século XIV. Entretanto, só no século XIX a Música Programática transforma-se em rival da chamada "música absoluta" ou "música abstrata", que utiliza apenas seus próprios recursos. Exemplo obrigatório de Música Programática, em sua variante sinfônica, é a Sinfonia Fantástica de Hector Berlioz. (1803-1869). O programa dessa sinfonia narra a história de um jovem músico, que, obcecado por uma paixão amorosa, embriaga-se com ópio. Adormecido, é atormentado por um pesadelo. Sente-se assombrado por entes demoníacos e também pela lembrança da mulher amada, representada por uma melodia recorrente, a "ideia fixa", espécie de leitmotiv, que confere unidade à composição.

Segundo o programa, o primeiro movimento da Sinfonia Fantástica, um allegro denominado "Devaneios e Paixões", representa o artista atormentado por um 
desejo indefinível. Dele resulta a mórbida paixão por uma jovem, melodicamente associada à "ideia fixa". Seguem-se o lento largo, o tumultuado allegro agitato e o arrebatado appasionato - que sugerem as sucessivas emoções do personagem.

O segundo movimento, "Um Baile", inicia-se com uma valsa, num brilhante allegro ma non troppo, representando uma festa em que o artista reencontra a amada - a "ideia fixa". A seguir, um dueto pastoral, composto com fragmentos de música folclórica, evoca um momento de suave tranquilidade, logo minado pela suspeita de infidelidade da jovem.

O terceiro movimento, "Marcha para o Cadafalso", descreve a punição do artista por ter assassinado a amada. O allegretto non troppo lembra uma marcha fúnebre, indicando a caminhada do artista para o patíbulo, sempre atormentado pela "ideia fixa".

"Sonho de uma Noite de Sabát" - o último movimento - inicia-se com um larghetto. Na sequência, um tumultuoso allegro assai convida o ouvinte a imaginar uma orgia fantasmagórica, com espectros e feiticeiras acompanhando o cortejo fúnebre. O dobre de um sinistro Dies Irce funde-se com gemidos, gargalhadas, gritos distantes, integrando uma grotesca melodia de dança, que inclui a "ideia fixa", evocação da amada. .

Como um subtipo de Música Programática, mas divergindo dela por constarem de um único movimento, citam-se os poemas sinfônicos; inspiram-se frequentemente em textos literários, indicados apenas pelo título da composição. Entre os inúmeros exemplos, encontram-se Romeu e Julieta (1880), de Tchaikovsky, Sonho de uma Noite de Verão (1826), de Mendelsohn, A Tarde de um Fauno (1894), de Debussy, Macbeth (1886-1888), Don Juan (1888) e Don Quixote (1897), de Richard Strauss. Nas composições inspiradas por peças de Shakespeare, os personagens são muitas vezes associados a determinados instrumentos. $\mathrm{Na}$ Tempestade (1926) de Sibelius uma combinação de harpas e percussão representa a hesitação de Próspero entre impulsos malignos e tendências benevolentes. As heroínas são tradicionalmente associadas às madeiras, transformadas em significantes trágicos, luto ou melancolia. Em Hamlet, de Edward German (1897), a presença de Ofélia é simbolizada pela clarineta, em contraste com os metais e os instrumentos de percussão, que anunciam um Hamlet viril e militarizado. Os instrumentos de sopro de madeira são também usados por German para representar Julieta, tal como ocorre no Romeu e Julieta (1839) de Berlioz. O mesmo acontece ainda com Desdemona no Othello (1892) de Antonin Dvořák, contrastando com as notas agourentas do contrabaixo, que indicam a entrada do Mouro na alcova conjugal. A seguir, sons do oboé sugerem a voz de Desdemona protestando inocência, e, depois, as notas da flauta, anunciando sua submissão e morte. No 
estudo sinfônico, Falstaff(1913), de Edgar Elgar a clarineta plangente associa-se à morte do protagonista, após sua rejeição por seu antigo amigo, Henrique V, proclamado rei. Pelo menos essa foi a opinião de A. C. Bradley - um dos vários críticos literários do século XIX que influenciaram a interpretação de adaptações musicais. O emprego da Música com objetivos simbólicos destaca-se também em óperas e outras composições. Tal como, na peça de Shakespeare, o Otelo da ópera de Verdi (1887) gradativamente assume a linguagem de Iago: passa a ser representado por trechos musicais semelhantes aos referentes ao caluniador, sinalizando sua crescente influência sobre o Mouro.

\section{Literatura $e$ Música: a canção}

Na segunda parte da tipologia de Scher, Literatura $e$ Música, o próprio nome remete a configurações em que as duas artes se integram, na música vocal. Ao lado de oratórios, cantatas, madrigais, coros e baladas, a canção destaca-se como a imemorial e a mais conhecida dessas composições. Seu estudo traz à baila uma questão crucial, a relação entre a estrutura verbal e a musical. Por sua complexidade, o problema tem inspirado posturas críticas contrastantes. Alguns teóricos consideram que, na canção, o elemento musical predomina sobre o verbal. Outros atribuem igual peso aos dois constituintes, enquanto um terceiro grupo enfatiza a tensão entre melodia e letra.

Sem negar a contribuição do elemento verbal, Susanne K. Langer alinha-se entre os que sustentam a supremacia do constituinte musical. Segundo a filósofa norte-americana, quando palavra e música se fundem numa canção, todo o material verbal - fônico, semântico, poético ou estrutural - é assimilado pelo musical. Não se pode mais falar de linguagem verbal ou de Poesia, mas tão somente de Música. Assim, ao escutar uma composição sacra, mesmo quando totalmente ignorante da língua grega, o ouvinte apreende o peso expressivo de palavras como Kyrie Eleison. Essa assimilação do elemento verbal pelo musical explica a razão pela qual, na música vocal, versos banais podem funcionar tão bem como grandes poemas. Por isso, canções de Schubert tendo como letras versos medíocres de Müller não se mostram inferiores às que exploram poemas de Shakespeare e de Heine. Langer (1953, p. 150-153) chega a afirmar que, para o compositor, um poema perfeito pode até constituir um problema, pois a preservação da forma literária interfere na criação musical. No Brasil, Mário de Andrade, como a filósofa americana, defende a primazia do elemento musical. A propósito, argumenta o crítico, na canção o ritmo musical jamais se submete ao da palavra. Nos rituais religiosos, pouco importa o significado das frases cantadas. Termos latinos, usados na liturgia católica, desempenham função equivalente à de palavras cabalísticas 
e glossolalias, encontradas tanto nas fórmulas sacras do antigo Egito como um canto de catimbó de nossos dias. (Andrade, 1980, p. 21).

Em posição diversa, outros teóricos atribuem igual peso ao elemento verbal e ao musical, salientando a integração entre textualidade e musicalidade, com a indispensável sincronização do acento musical e o métrico. Em sua obra O Cancionista (1996, p. 208), Luiz Tatit afirma que a especificidade da canção reside precisamente na interação dessas duas forças - sequências melódicas e unidades linguísticas - cuja justaposição e tensão transformam a fala em canto. Compor uma canção significa, pois, eliminar a fronteira entre os dois. Combina-se assim, a continuidade linear da melodia, cujo fluxo se adapta naturalmente às vogais da linguagem verbal, com a fricção e a descontinuidade oferecidas pelas consoantes, que segmentam o discurso verbal em fonemas, palavras, locuções, etc. O compositor, conclui Tatit, deve amalgamar num todo único a articulação linguística e a continuidade melódica. A propósito, o musicólogo cita a afirmação de David Treece: durante a audição, é impossível dissociar música e linguagem verbal; o ouvinte reconhece as inflexões efetuadas pelo compositor como se nascessem da estrutura melódica subjacente. Assim, nas melhores canções, a melodia parece brotar espontaneamente do texto verbal. (Tatit, (1996, p. 208)).

Como exemplo da integração entre a construção musical e a verbal, cito a canção de Chico Buarque de Holanda, "Malandro" que introduz sua comédia musical Ópera do Malandro (1978). A canção homônima distingue-se especialmente como projeção da figura de um ícone da cultura brasileira, o malandro. Conhecido por seus dons de argúcia, encanto e lirismo, ele tem sido interpretado como figura liminar entre a ordem e a desordem, não raro associada à cultura nacional. A melodia de "Malandro", tomada de empréstimo à canção "Die Moritat Von Mackie Messer" ("Balada de Mack Punhal"), composta por Kurt Weill para a Die Dreigroschenoper (A ópera dos três vinténs, 1928) de Bertolt Brecht, é transcriada pelo compositor brasileiro em ritmo de samba, repetindo quase monotonamente a melodia de "Moritat". Sua função é dividir a composição nos diversos segmentos rítmico-melódicos, que coincidem com as subdivisões da letra em estrofes. Essas constam de versos heptassilábicos, típicos do cancioneiro popular, com os tempos fortes uniformemente marcados na terceira e na última sílaba de cada verso. A adoção do ritmo de samba, adequado à construção de figuras folclóricas brasileiras como a baiana e o próprio malandro, é a principal metamorfose introduzida por Chico Buarque na criação de Kurt Weill. O compositor brasileiro transforma as personagens da peça inglesa em diferentes versões do malandro.

A letra do samba que inicia a Ópera brasileira apresenta o malandro como figura emblemática dos grupos explorados no mundo globalizado. Na criação 
de Chico Buarque, essa figura é ambivalente: pode associar-se a grupos ética e socialmente antagônicos, no cenário nacional e internacional. De um lado, encontram-se os pequenos malandros, que são vítimas dos grandes malandros, assentados nos centros do poder. A letra da canção descreve o processo de exploração em toda a cadeia socioeconômica produtiva. Menciona primeiro um pequeno malandro, caloteiro, demasiado pobre para pagar a cachaça que consome. Sucessivamente, o texto cita outros personagens, integrantes da cadeia ascendente de malandragem: o produtor da bebida, o usineiro - os intermediários - botequineiro, distribuidor - até chegar aos exportadores e eventuais importadores. No hemisfério norte, são estes os grandes malandros, os exploradores, que controlam o mercado internacional e barram o produto brasileiro.

As primeiras quadras da letra, no "Prólogo" do Primeiro Ato, relatam:

$\mathrm{O}$ malandro / $\mathrm{Na}$ dureza

Senta à mesa /Do café

Bebe um gole/ De cachaça

Acha graça /E dá no pé

O garçom no/ Prejuízo

Sem sorriso/Sem freguês

De passagem/Pela caixa

Dá uma baixa/No português

O galego/Acha estranho

Que o seu ganho /Tá um horror

Pega o lápis/Soma os canos

Passa os danos /Pro distribuidor

Mas o frete/Vê que ao todo

Há um engodo/Nos papéis

E pra cima/Do alambique

Dá um trambique/De cem mil réis

O usineiro/Nessa luta

Grita puta/Que o pariu

Não é idiota/Tranca a nota

Lesa o Banco/Do Brasil.

Nosso banco/Tá cotado

No mercado/Exterior

Então taxa/A cachaça

A um preço/ Assustador

Mas os ianques/ 
Com seus tanques

Têm bem mais o/ Que fazer

E proíbem/ Os soldados

Aliados /De beber.

A partir desse ponto, a letra narra a reversão da série de golpes que compõem a cadeia da

exploração. Refazendo, em sentido inverso, o caminho percorrido, o texto repassa os elos anteriores: banqueiros, exportadores, usineiros, portuários, botequineiro - até a parte mais fraca da corrente, o malandro caloteiro. Ele e um garçom, modesto assalariado, são os únicos penalizados. Para os demais, vale a impunidade. As quadras finais descrevem a inversão do processo:

A cachaça /Tá parada

Rejeitada/No barril

$\mathrm{O}$ alambique/Tem chilique

Contra o Banco /Do Brasil.

$\mathrm{O}$ usineiro/Faz barulho

Com o orgulho /De produtor

Mas a sua /Raiva cega

Descarrega/No carregador.

Este chega/Pro galego

Nega arreglo /Cobra mais

A cachaça /Tá de graça

Mas o frete /Como é que faz?

O galego /Tá apertado

Pro seu lado /Não tá bom

Então deixa/ Congelada

A mesada/Do garçom.

$\mathrm{O}$ garçom vê/Um malandro

Sai gritando /Pega ladrão

E o malandro /Autuado

É julgado e condenado culpado

Pela situação.

"O desenrolar da canção evidencia a integração dos constituintes verbal e musical, como atesta a gravação à qual me refiro, "O Malandro" no CD Ópera do 
Malandro da Polygram, remasterizada em 1986. A crítica implícita na letra articula-se com virtualmente todos os elementos da composição musical: o ritmo, o desenho melódico, a intensidade e a duração das notas, o número e volume de vozes, o estilo interpretativo, bem como, na quadra final, a utilização do breque, caracterizado por ritmo sincopado, com interrupções bruscas, destinadas à fala ou improvisação do cantor, sem acompanhamento musical. Na gravação mencionada acima, a voz é do próprio Chico Buarque. Ele canta acompanhado de violão e pequeno conjunto, em andamento moderado, no estilo do "canto falado" ou "cantar baixinho", reminiscente da Bossa Nova .O timbre e o reduzido volume da voz do cantor simulam o tom de conversação, compatível com a coloquialidade da letra A mesma frase melódica, tomada de empréstimo à "Moritat" de Weill, reaparece duas vezes em cada verso. Pausas musicais, coincidentes com a pausa métrica em cada heptassílabo, bem como a maior intensidade e duração da última nota, indicam o fim e o iminente reaparecimento de cada ocorrência melódica. Esta termina com um tonema ascendente, suspensivo, que sugere a continuidade do processo, como convém ao caráter cíclico da exploração, denunciada pela letra. Acompanhamento e canto valorizam-se mutuamente, nas breves pausas expressivas. $\mathrm{O}$ ápice do processo narrativo, assinalado pela referência da letra à chegada da cachaça ao mercado internacional, coincide com o clímax musical: nesse ponto, crescem gradativamente o volume e o número das vozes.

Verifica-se o mesmo entrelaçamento entre textualidade e musicalidade quando a letra descreve a volta da cachaça a seu ponto de origem, repassando, em sentido inverso, os elos da cadeia de exploração. $\mathrm{O}$ andamento desacelerado e a menor intensidade da execução coincidem com esse movimento. No final, aumentam novamente o número e o volume de vozes, sublinhando o acordo geral para a condenação do malandro explorado. As palavras já não são cantadas, mas faladas, como no samba de breque. Sabidamente, o breque, popularizado por Moreira da Silva em 1936, como lugar da improvisação, sugere liberdade, em contraste com a marcha, associada à disciplina do trabalho. Essa ideia de liberdade, coincidente com o final do samba, adapta-se como uma luva à temática da Ópera de Chico Buarque. Reafirma o vínculo inextricável entre letra e composição musical, textualidade e musicalidade, geminadas na canção. - a forma de arte mais expressiva da vida cultural brasileira.

\section{Música na Literatura}

\subsection{Música de Palavras}

Considero, finalmente, a última categoria proposta por Scher, que se subdivide em três tipos: Música de Palavras, Música Verbal e Imitação de Estruturas Musicais. 
Como "Música de Palavras" entende-se qualquer construção sonora autoreferencial, resultante da exploração do aspecto material da linguagem poética, ou, como quer Scher, a imitação, pela linguagem verbal, da qualidade acústica de sons musicais exemplificada pela onomatopeia. A propósito, cito a lúdica exploração do estrato fônico embutida na poesia de Manuel Bandeira. Não sem razão, autor de "Os sapos", hino oficial do Modernismo, ele é considerado o mais musical dos poetas brasileiro. Veja-se, por exemplo, o jogo de assonâncias, consonâncias e aliterações em "Berimbau", de O ritmo dissoluto.

Os aguapés dos aguaçais

Nos igapós dos Japurás

Bolem, bolem, bolem.

Chama o saci: - si si si si!

- Ui ui ui ui ui! uiva a uiara

A mameluca é uma maluca.

Saiu sozinha da maloca -

O boto bate - bite bite.

Quem ofendeu a mameluca?

- Foi o boto!

(Bandeira, 1986, p. 196).

Como negar a musicalidade desse poema? Mais que o sentido, a música das palavras puxa a linha do verso, fazendo a dimensão semântica brotar do borbulhar sonoro. Coerente com o predomínio do estrato acústico sobre o semântico, típico da "Música de Palavras", o texto inteiro reverbera com a exploração de assonâncias, consonâncias e aliterações estrategicamente situadas. O chamado do saci evoca a última nota da escala de dó. A interjeição "ui!" gera a forma verbal "uiva" e o substantivo "uiara". O adjetivo "maluca" nasce do nome "mameluca", no jogo de "palavra puxa palavra", que se surpreende também na poesia de Carlos Drummond de Andrade. Ao fim e ao cabo, toda essa pirotecnia sonora contribui para evocar a paisagem da Amazônia, com suas figuras lendárias.

\subsection{Imitação literária de estruturas musicais}

A imitação de estruturas musicais - outro tipo de Música na Literatura, conforme a tipologia de Scher - também se faz presente na obra de Manuel Bandeira. O poeta recorre a modelos musicais para a estruturação de seus poemas, particularmente a técnica denominada "tema e variação". A propósito, este é o título de um poema seu, incluído em Opus 10 (Bandeira, 1986, p.296), outro título claramente indicativo de inspiração musical. Vamos à leitura: 
Tema e variações

Sonhei ter sonhado

Que havia sonhado.

Em sonho lembrei-me

De um sonho passado:

O ter sonhado

Que estava sonhando

Sonhei ter sonhado.

Ter sonhado o que?

Que havia sonhado

Estar com você.

Estar? Ter estado

Que é tempo passado.

Um sonho presente

Um dia sonhei.

Chorei de repente

Pois vi, despertado,

Que havia sonhado.

Ao compor o poema e atribuir-lhe título tão inequívoco, Bandeira, crítico grande conhecedor da teoria musical, tinha certamente em vista o sentido técnico de "Tema e Variação". Para os musicólogos, "tema" é a ideia musical que atua como ponto de partida para uma composição, especialmente a sonata - integrante de sinfonia, quarteto de cordas, etc.- a fuga ou as chamadas variacionais (variation forms), como a chacona, a passacaglia e o basso ostinado, rapsódia, contraponto e fuga. A variação consiste na repetição do tema, com alguma alteração, na melodia, na harmonia, em ambas, etc..

O núcleo semântico do poema - o paradoxal sentimento de perda e de preservação de uma experiência passada - é introduzido por uma espécie de mote, constituído pelo verso inicial, "Sonhei ter sonhado". Esse verso, instituindo-se como um tema semelhante ao de uma composição musical, sofre uma série de acréscimos e reformulações, que constituem as variações. Elas surgem inicialmente nos doze versos que contêm uma forma cognata de "sonhei", primeira palavra do poema. A variação consiste inicialmente na mudança do tempo verbal ou da 
categoria gramatical correspondente a essa palavra-chave. Dos cinco versos restantes, dois ligam-se gramaticalmente aos anteriores, por conter igualmente uma variação da forma verbal ("Estar com você? /Estar? Ter estado"), enquanto outro verso ("Que é tempo passado") cria um trocadilho com os dois sentidos da locução "tempo passado": o sentido gramatical de "forma verbal pretérita" e a significação genérica de "espaço cronológico anterior ao momento atual". Remetendo também ao duplo sentido, o gramatical e o cronológico, da palavra "presente", o verso "Um sonho presente", resume a perfeita integração do conjunto forma/ conteúdo que constitui o texto. Ficam assim enfatizadas tanto a natureza evanescente da temporalidade quanto a dúvida sobre a possibilidade de se recuperar, pela memória, uma experiência amorosa, condicionada por essa temporalidade. A temática da vida como duplo questionamento da realidade - sonho dentro de outro sonho - mostra-se assim inseparável da técnica utilizada.

No Brasil, encontram-se facilmente estudos de obras literárias construídas à semelhança de tema e variações, formas como fuga e contraponto, e também construções mais livres, como a rapsódia. Destaco a análise do romance de Mário de Andrade, Macunaíma, (cujo subtítulo é exatamente "Uma rapsódia") por Gilda de Mello e Sousa. No estudo O tupi e o alaúde (1979), a crítica estuda a transposição para Macunaíma de duas formas básicas da música ocidental, comuns tanto à criação erudita quanto à popular: o princípio rapsódico da suíte e o princípio da variação, este último presente, de modo muito peculiar, no improviso do cantador nordestino. Mello e Souza estuda longamente a utilização por Mário de Andrade do processo da suíte - "a técnica de construir recheando o núcleo básico com temas subsidiários, com várias peças de forma e caráter distintos", nas personagens e na dubiedade das ações. (Melo e Souza, 1979, p. 37). Outro crítico, Silviano Santiago, que cita o trabalho de Mello e Souza, faz uma análise semelhante de Clarissa, demonstrando que, como Macunaíma, o romance de Érico Veríssimo exibe uma estrutura musical semelhante à rapsódia, visando "combinar em harmonia elementos variados, de forma que exista uma composição do todo que não seja mero produto de acúmulo." (Santiago, 1986, p. 164-165).

Outra forma utilizada por poetas e romancistas, para a estruturação de seus textos, é a sonata. Em sua construção clássica, consiste na exposição de um tema básico, no desenvolvimento desse material e uma recapitulação, ocasionalmente seguida de uma coda. Para alguns musicólogos, a principal característica da forma sonata é uma exposição, com dois temas contrastantes. No desenvolvimento, os dois entram em conflito, sendo retrabalhados para criar uma tensão, que é resolvida na recapitulação. Para outros teóricos, a questão central é o conflito, não de temas, mas entre áreas tonais. 
Entre os críticos brasileiros, Maria Luiza Ramos aponta no romance Maíra, de Darcy Ribeiro, uma estruturação modelada na forma sonata. Segundo a autora, o romance desenvolve dois temas - a cultura indígena e a chamada civilização - que são contrapostos por tonalidades distintas: Diferenciando-se do contexto indígena, o contexto civilizado é marcado por um discurso referencial, pontuado, às vezes, por clichês burocráticos do registro policial. A propósito, a autora argumenta que, no contexto civilizado,

... o que importa é informar, devendo, pois, a linguagem acompanhar a rapidez com que se sucedem os fatos. Por outro lado, espelhando logo depois a atemporalidade do mundo mítico, que caracteriza o segundo tema, o discurso é lento e poético. As pausas e as frequentes repetições instauram, na recursividade da linguagem, voltada para si mesma, a densidade dos ritos no mundo fechado das sociedades primitivas. Como se dá na forma sonata, há um contraste entre as duas linguagens, desde uma diferença tonal até um diversificado tratamento rítmico. (Ramos, 2000, p, 142).

\subsection{Música Verbal}

Resta-me discutir o terceiro tipo de relação músico- literária proposto por Steven Paul Scher. Refiro-me à "Música Verbal", definida como a criação literária descritiva da recepção da obra musical por um ouvinte atento, ou, na formulação de Scher, a "apresentação literária (em poesia ou prosa) de composições musicais, reais ou fictícias." Além de equivalentes verbais de criações reais ou imaginárias, esses textos frequentemente sugerem a reação subjetiva do autor implícito ou de um personagem a uma execução musical.

A Música Verbal comparece frequentemente na ficção brasileira. Reflexos do Baile, romance de Antonio Callado, oferece um exemplo muito ilustrativo, representando a reação de Carvalhaes, embaixador português em visita a uma escola brasileira, quando, por acaso ouve um uma melodia, um choro, executado á distância. O trecho abaixo, exemplo de Música Verbal, além da alusão a elementos rítmicos, melódicos e compositivos, destaca a percepção dos traços subversivos que o personagem apreende no choro. Sua intuição harmoniza-se com a história, pois o choro nasceu da recriação transgressora de modelos europeus apropriados por brasileiros. Eis como o embaixador descreve sua audição da música sedutora, povoada de "perigosos, dissolventes anjos":

...notas musicais puseram-se a estalar e crepitar como gomos de bambu deitados às chamas. Uma toada amorosa, cheia de requebros, mas enquadrada em composição sonora de tão alarmante rigor que perguntei ao meu descompassado coração se se afinal cá existem dementes a tentar tudo recomeçar de novo. Franziu o cenho o diretor da escola diante dos perigosos, dissolventes anjos que a música soltava entre as crianças de uniforme. (Callado, 1976, p. 18-19). 
Essa descrição assinala a intuição, por parte do personagem, dos elementos revolucionários do choro. Deformação irreverente de modelos europeus, essa forma de música instrumental popular mostra-se ideal como emblema da postura subversiva de todos os personagens do romance, o que desagrada ao reacionário diretor do colégio visitado pelo embaixador. Desponta aqui, simultaneamente, um exemplo de relação músico-literária, que não é objeto da abordagem de Paul Scher: o da metáfora musical.

A propósito, Scher reconhece que seu esquema não contempla tópicos importantes, como o papel da Música na sinestesia (interpretação poética de experiências musicais em termos de cores ou de imagens visuais), e a crítica musical produzida por autores como Hoffmann, Stendhal, G.B. Shaw e Ezra Pound. A categorização de Scher também não explicita a possibilidade de correlações históricas, como a influência da música sobre períodos literários e autores específicos, ou estudos diacrónicos envolvendo periodização, recepção e disseminação. Muito menos considera construções ambivalentes, situadas entre a Música e a Poesia, como na Poesia Sonora e na Música Concreta, mencionadas a seguir.

\section{Poesia sonora ou música concreta?}

O mundo contemporâneo, inclinado a abolir fronteiras entre artes e mídias, franqueia ao artista total liberdade na manipulação do som. Abre-lhe, entre outras, a possibilidade de voltar a explorar material acústico de forma ambivalente, apagando distinções entre Poesia e Música. Os prenúncios desse fenômeno já se encontram na poesia fonética das vanguardas históricas, no dadaísmo e no futurismo. como no "verso sem palavras", ou "poemas de som", criados por Hugo Ball no Cabaret Voltaire em 1915. Posteriormente, surgiram precursores do que se viria a chamar Poesia Sonora, entre os quais Henri Chopin, Bob Cobbing e Ada Verdun Howell. Para poemas desse tipo, dotados de atributos mais puramente sonoros que literários, e basicamente desprovidos de traços semânticos, Edith Sitwell cunhou o termo "Poesia Abstrata". Em tais casos, afrouxa-se o vínculo entre palavra e sentido, modula-se, ou, frequentemente, inverte-se, a hierarquia convencional entre o sonoro e o semântico, sem que este seja necessariamente eliminado. Chegamos assim ao que hoje denominamos Poesia Sonora, definida provisoriamente como uma espécie de composição músico-literária, típica do século 20 - uma espécie de "verso sem palavras". Criada por improviso, como o jazz, e primordialmente destinada a performances, privilegia os elementos fonéticos, em detrimento dos aspectos semânticos e sintáticos da fala. Como vem ocorrendo com as artes em geral desde o início do século XX, a poesia entrega-se, assim, ao prazer da pura exploração de seu próprio material. 
Em seu percurso histórico, a Poesia Sonora recebeu um impulso significativo com a popularização, por volta de 1947, do gravador em fita magnética. Ele possibilitou criações como a longa série de "Cri-Rythmes", poemas fonéticos de François Dufrene (1930-1980), gravados diretamente em fita magnética. Totalmente desvinculados da escrita, soavam como mixagens feitas em estúdio.

A partir dos anos 60, a obra do compositor Luciano Berio (1925-2003) anuncia a Poesia Sonora que hoje conhecemos. Bob Cobbing (1920-2002), outro entusiasta do uso do gravador e do microfone, igualmente sonhava com uma criação avessa ao intelecto, que desatasse o laço entre o som e o sentido - uma poesia de puro som, como proclama em seu manifesto de 1969, "We aspire to birdsong" ("Aspiramos à canção dos pássaros"). Mais ou menos à mesma época, no grande espetáculo de leitura de poesia no Albert Hall, em Londres, em 1964, Ernst Jandl (1925-2000) surgiu como o criador mais acessível da Poesia Sonora contemporânea, apartado do tratamento de choque e dos nonsense sounds dos dadaístas e de seus descendentes. Jandl, poeta prolífico e performer expressivo, publicou em 1970 o volume Derkünstliche Baum (A árvore artificial) acompanhado de um disco. A antologia incluía poemas visuais, um texto para leitura, composto com escritas encontradas em lápides de cemitério e em material de propaganda, e poemas sonoros - "um texto para ser recitado". A interpretação dada por Jandl a esse texto multilíngue, intitulado "Teufeslfalle", e analisado por Claus Clüver (2000, p. 39) oscila entre recitativo e canto, e evoca algumas observações de Paul Zumthor: a poesia sonora confirma a tendência contemporânea a cancelar as fronteiras entre as artes. Descartados "os falsos pudores da poesia de inspiração tradicional" (palavras de Zumthor), essa poesia recorre, através da voz e dos órgãos fonadores, a "todos os rumores do corpo... do sopro esofágico ao sopro bronquial e aos arquejos ventrais... quando o corpo inteiro torna-se significante". (Zumthor, 1992, p. 139, 141, 142).

Um fenômeno semelhante manifesta-se nos anos 80, com a aproximação entre poesia sonora e a language poetry norte-americana, que remete às criações de John Cage (1912-1992). Essencialmente experimentais, no caminho trilhado por Marcel Duchamp, confirmam a tendência para a fusão entre Poesia e Música A arte de Cage instaurou uma nova concepção de Música, apoiada na contribuição do acaso: incluía todos os tipos de sons, até ruídos ocasionais, à semelhança de experiências de William Carlos William com a poesia. Nos anos 60, Cage cultivou uma poesia cujos métodos incorporavam tanto princípios intencionais como não intencionais. Sua técnica em "Writing through the Cantos" faz pensar na construção musical de Schoenberg. Na exposição de seus princípios, nem sempre é fácil decidir se Cage fala de música ou de poesia. Às vezes utiliza o texto 
literário como simples matéria prima para algo que tanto se pode considerar Poesia Sonora (Sound Poetry) quanto Música Concreta (Concrete Music). É o que se vê em sua manipulação de textos de James Joyce e Ezra Pound para composições baseadas no acaso.

Claus Clüver analisa minuciosamente vários exemplos dessa prática, que inclui justaposições, inversões, transformações, repetições com variações de padrões rítmicos e sonoros. Algumas composições são acompanhadas por algo semelhante a partituras de peças musicais contemporâneas. Descartam a notação tradicional para recorrer a novas formas de escrita musical, específicas de cada criação, que indicam duração, intensidade, altura e até o modo de desempenho do texto sonoro. Em seu ensaio, Clüver retoma a conclusão de Franz Mons sobre a função da manipulação eletrônica de sons: "ela começou a dissolver os limites aparentemente estáveis entre Música e linguagem verbal. Compositores usaram material linguístico, autores empregaram princípios de composição musical" [...] especialmente em alguns exemplos de Música Concreta e de música eletroacústica: hesitamos em classificá-los como Poemas Sonoros ou como Música Concreta." (Clüver, 2002, p. 170, 173)

Também o rap, às vezes com versos rimados, mas sem registro escrito, ressuscita a indagação: trata-se de Poesia ou de Música? A pergunta torna-se cada vez mais pertinente, com a crescente interface entre a Poesia e as novas tecnologias, já ilustrada pelo Festival Internacional de Poesia Sonora realizado em Stockholm em 1967. Em alguns casos, os poetas anunciavam os títulos, ligavam o gravador e voltavam quarenta e cinco minutos depois, para desligar o aparelho e encerrar a "recitação". No Brasil, no Paço das Artes de São Paulo, em 1998, Philadelpho Menezes organizou um evento semelhante, intitulado" Poesia Intersignos".

Nesse campo de investigação, Menezes oferece esclarecimentos cruciais. Rememora a vinculação histórica da Poesia Sonora com a poesia fonética das vanguardas futuristas e dadaístas do início do século XX. Recapitula também os princípios subjacentes, que remetem a manifestações ancestrais: a Poesia nasce bem antes do texto e do discurso e não depende deles para existir. A palavra é apenas um de seus constituintes possíveis. Bastam-lhe conjunções sonoras, organizadas numa certa ordem, sugerindo sensações, impressões, conceitos.

Como denominador comum às várias vertentes de Poesia Sonora, Menezes aponta seu caráter essencialmente experimental e oral, que a distingue claramente de formas tradicionais de declamação. Em lugar delas, privilegiam-se o humor, as técnicas fonéticas e a utilização de recursos tecnológicos. Destaca-se a importância da integração do Poema Sonoro com mídias e linguagens: espaço, gestualidade, vídeo, interação com o público. Entretanto, Menezes insiste num 
ponto crucial, que não vi enfatizado por qualquer outro teórico: todos os elementos citados devem subordinar-se ao projeto do poema. $\mathrm{O}$ processo privilegiado não será de multimídia, de colagem, mas de montagem, de relação intersígnica. Ao contrário do que ocorreu nos anos 1950, quando Henri Chopin criou o nome "Poesia Sonora" para seus poemas em aparelhagem eletroacústica, em nossos dias, segundo Menezes, revê-se o papel da tecnologia. Ainda que extremamente útil, ela deve subordinar-se aos objetivos do poema, rejeitar os efeitos eletroacústicos como um fim em si mesmo e enfatizar as possibilidades expressivas do corpo e da voz. Em resumo: não se deve perder de vista a complexidade semântica da comunicação poética.

Nem sempre ligados à vertente experimental, vários poetas contemporâneos, de formas e em graus diferentes, observam o preceito de Menezes. Ressaltam sua ligação com a Música, sem descartar o vínculo entre som e sentido. Lembro aqui o nome de Marcos Bagno, que assinala sua "filiação simbolista", certamente evocando a ênfase do Simbolismo nos efeitos musicais da linguagem verbal. Bagno (1991, p. 247) afirma colher poesia nas palavras, “em estado de dicionário, latentes, plenas de vida possível", mas também na "música, signo oco, assemântico... mais que perfeita".

Há que lembrar ainda a natureza híbrida de algumas criações. Em 1996/1997, Ricardo Corona, juntamente com o guitarrista Johnny Tequilla apresentou o show poético-musical Poesia'n'roll. Em Simbolista, poema de celebração a São Paulo, carregado de referências poéticas e musicais, Corona recapitula a velha afinidade entre poesia e música decantada por Verlaine. A voz poética declara aspirar a

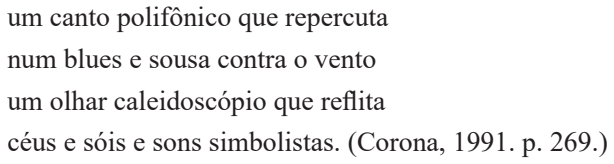

Urge falar também da criação contemporânea não experimental, que, facilitando a compreensão, permite a exploração dos temas mais diversos. Na Literatura Pós-colonial, saltam á vista metáforas derivadas da Música. Metaforizam-se assim tópicos cruciais, como a hibridez, o choque entre culturas, a opressão (neo) colonial e a construção de identidades pós-coloniais. A título "de exemplo, cito o conto "Visiting", do escritor caribenho Roger Mc Tair. O autor recorre ao Calipso como metáfora do turismo sexual no Caribe. Outro conto, Easter Sunday morning, da escritora jamaicana Hazel Campbell, explora o diálogo entre música europeia e a canção caribenha, emblemático do embate entre as respectivas culturas. No romance Los pasos perdidos, de Alejo Carpentier, o tema da busca da 
origem da música remete ao anseio por uma mítica identidade latino-americana, não contaminada pela influência europeia. Entre os escritores que, como Carpentier, exploram a dimensão metafórica da música de nações outrora colonizadas, destaco o norte-americano Steven Feld, que deve muito ao estudo de rituais e folclore africanos, bem como aos ritmos e repetições do jazz. No ensaio "Sound and sentiment, sound and symbol”, que passo a resumir, o músico e antropólogo rememora a origem comum de Música e Poesia. Ao refletir sobre suas relações, retoma as observações de poetas e sua aspiração a transcender o verbal para atingir a condição da Música.. Nesses textos, associam-se questões sociais e metafísicas. A implicação social é ilustrada pela concepção de discurso musical implícita no gisalo, forma de canto peculiar aos povos Kaluli, da Nova Guiné, privilegiada em funerais e sessões mediúnicas. Para os Kaluli, essa música, expressão simultânea de lamento e consolo, brota de uma espécie de orfandade, a perda de laços sociais. Feld encontra algo semelhante na música dos negros, de spirituals como "Motherless child" (Criança órfã), inspirados em outra orfandade simbólica, a discriminação pelo racismo. No mesmo sentido, refere-se à observação de Julia Kristeva sobre a importância do ritmo na linguagem poética: o ritmo visa levar a Poesia a apreender aquilo que não significa, torná-la independente do signo, livrá-la da denotação - como na Música. É por isso, conclui Feld, que, no mito dos Kaluli, a origem da Música é também a da Poesia. Essa conclusão nos devolve ao ponto de partida, o parentesco entre as duas artes, mais que nunca inseparáveis.

\section{Estudos Músico-Literários e Estudos de Intermidialidade}

Do ponto de vista teórico, este ensaio estaria incompleto, se, além dos textos de Steven Paul Scher, publicados entre os anos 1960 e 1980, não recorresse a teorias mais recentes, baseadas no conceito de Intermidialidade. Sucedendo aos Estudos Interartes, embora sem exclui-los, os de Intermidialidade visam simplesmente tratar das relações entre as mídias. Furtam-se, assim, à espinhosa conceituação de "arte", já que nem toda mídia constitui arte, embora toda arte exija o emprego de mídias. Na esteira desse raciocínio, buscando resumir uma abordagem intermidiática da relação entre Literatura e Música, destaco um texto de Werner Wolf, que se apoia em trabalhos de Irina Rajewsky e do próprio Steven Paul Scher.

Segundo Wolf (2015 p. 460), a tipologia proposta por Scher para os estudos músico-literários, embora muito anterior aos Estudos de Intermidialidade, tem permanecido basicamente reconhecível em todas as reformulações teóricas. Sua própria abordagem, confessa Wolf, preserva boa parte das categorias formuladas por seu antecessor. Embora enriquecida por acréscimos e subdivisões, o autor mais recente contenta-se em situá-las no campo da Intermidialidade. Um dos 
acréscimos diz respeito ao que denomina Intermidialidade Extracompositiva, na qual as relações intermidiáticas transcendem obras individuais. É o caso das transposições intermidiáticas, quando o conteúdo, ou a estrutura formal, é transposta de uma para outra mídia. O exemplo clássico é o de filmes ou de óperas originárias de romances. Igualmente situada no campo da Intermidialidade Extracompositiva, Wolf menciona a Transmidialidade, isto é, a ocorrência, em várias mídias, de fenômenos que não são específicos de qualquer delas, tais como a presença de uma narrativa, ou de um narrador, em uma obra literária, numa ópera, num filme, num balé, etc.

Por outra lado, Wolf considera a Intermidialidade Intracompositiva, que ocorre no âmbito de uma única obra, e se subdivide em Plurimidialidade e Referência Intermidiática. Entre as referências implícitas, Wolf situa Evocação e Imitação Formal, claramente correspondentes à Música Verbal e à Imitação de Estruturas Musicais na tipologia de Scher. Fora essas, também tratadas como ocorrências de Intermidialidade Intracompositiva, Werner estuda referências parciais (exemplificada pela citação da letra de uma canção), e referências explícitas (uma discussão sobre a Música no texto de um romance), além de outros fenômenos, como a Plurimidialidade - caso da canção, que integra duas mídias, a verbal e a musical. Além dessas Wolf define interrrelações não nomeadas, mas implícitas, no esquema de Scher, como acontece com a Canção.

Considero cruciais as observações finais de Werner sobre a impossibilidade de esgotar o estudo de todas as possibilidades da Intermidialidade na Música. Encontramos aqui sugestões de temas para pesquisas futuras. Entre esses parecem-me especialmente interessantes os seguintes:

- a gênese da intermidialidade

-a discussão sobre a importância relativa de uma mídia em relação a outras -pesquisas centradas na figura do autor/compositor ou do leitor/ouvinte -funções das relações intermidiáticas -compilação de um dicionário de relações músico-literárias.

\section{Conclusão}

Em sua longa história, a arte verbal e a criação musical continuam a dar-se as mãos, em configurações que, adotando o esquema de Steven Paul Scher, considerei sob o rótulo de Literatura e Música (Oliveira, 2012). Nascidas irmãs, as duas artes chegam a tornar-se siamesas na música experimental contemporânea, fundindo-se como poesia sonora ou música concreta. Essas formas, sem fronteiras discerníveis entre o verbal e o musical, assinalam um percurso cíclico, de 
volta e reformulação, reminiscente de vetustas práticas sociais, com seus cantos tribais, mantras e preces coletivas, encontrados ainda hoje nas chamadas culturas primitivas.

Ao considerar a união de Literatura e Música, voltei-me sobretudo para a Canção, que, ao contrário da poesia sonora, conjuga letra e melodia como elementos separáveis. Sem prejuízo de estruturações tradicionais, a partir dos anos 1960, essa forma imemorial enverga novas roupagens, como no rap ou nos jazz poems. Estes últimos são exemplarmente ilustrados por “The Raven”, canção de Alan Parsons e Eric Woolfson, que incorpora versos do poema de Poe, inclusive o refrão, "Qoth the raven, nevermore".

Seguindo o plano triádico de Scher, considerei a Música Programática, exemplo de Literatura na Música, como na Sinfonia Fantástica de Berlioz. Narrativa musicada das desventuras de um jovem apaixonado, essa composição pode ser ouvida como criação autônoma, lembrada por notáveis inovações harmônicas, sem referência a um programa escrito. Entre os poemas sinfônicos, executados como obras autônomas, embora inspirados em textos literários, destaquei o emprego de certos instrumentos usados para a representação de eventos e personagens. Finalmente, focalizei os três tipos de Música na Literatura esquematizados por Scher: Música de Palavras, Música Verbal e Imitação Literária de Estruturas Musicais. Em vários desses casos, o que sobretudo me interessa é a função desempenhada pela relação entre a Literatura e a Música. "Os Sapos", poema modernista de Manuel Bandeira, com seus divertidos efeitos onomatopaicos (exemplo de Música de Palavras) tem como função a sátira à poética parnasiana. A Imitação Literária de Estruturas Musicais (como os contrastes tonais da sonata no romance Maíra, de Darcy Ribeiro) sugere o contraste entre o contexto civilizado e o mundo dito selvagem. Em Reflexos do Baile, de Antonio Calado, a Música Verbal, associada ao efeito da música do choro sobre um dos personagens, funciona como emblema do texto como um todo, remetendo à luta de jovens revolucionários contra a ditadura militar dominante iniciada no Brasil em 1964. Uma luta semelhante, travada entre os povos subjugados e a dominação colonial, subjaz às metáforas musicais em textos de Literatura Pós-colonial, dos autores Roger Mc Tair, Hazel Campbell, Alejo Carpentier e Nathaniel Mackey, entre outros.

Lembrando as sugestões de Werner Wolf para que demos continuidade a esses estudos, reservo para pesquisas futuras o aspecto revolucionário de artistas como Benjamin Britten (1913-1976). Além de trazer ao século XX óperas inspiradas em obras literárias (A Midsummer Night's Dream (1960), Death in Venice (1973) Peter Grimes, (1945) (referência ao poema homônimo de George Crabbe), Curlew River (1964), inspirada pelo teatro Nô japonês). e Billy Budd (1951), título 
do conto de Herman Melville, Britten usou seu prolífico talento para assumir posturas políticas. Nesse sentido, destaca-se o réquiem não litúrgico War Requiem (1962), que, ao tradicional texto latino, justapõe versos de Wilfred Owen, denunciando o trágico absurdo da guerra. Esse aspecto da criação musical como instrumento de crítica à maior chaga de nossa civilização, parece-me o mais fascinante como tema para pesquisas futuras.

\section{Referências}

Andrade, Mário. (1980). Terapêutica Musical. Em Namoros com a medicina, organizado pelo autor, 21-23. Belo Horizonte: Itatiaia.

Bagno, Marcos. (1991). In principium erat verbum. Em Artes e ofícios da poesia, organizado por Augusto Massi, 241-254. Porto Alegre: Artes e Ofícios.

Bandeira, Manuel. (1986). O ritmo dissoluto. Em Poesia Completa e Prosa, organizado pelo autor, 181-197. Rio de Janeiro: Editora Nova Aguilar.

Bandeira, Manuel. (1986). Opus 10. Em Poesia Completa e Prosa, organizado pelo autor, 293312. Rio de Janeiro: Editora Nova Aguilar.

Brecht, Bertoltt. (1988). Die Dreigroschenoper. New York: Suhrkamp Pub Ny.

Brown, Calvin (1987). Music and Literature. London/Hanover: University Press of New England.

Cage, John. Themes and Variations (excerpts). (1994). Em Postmodern American Poetry, organizado por Paul Hoover, 616-626. New York and London: W. W. Norton \& Company.

Carpentier, Alejo. (1996). Los Pasos Perdidos. Madrid: Allianza Editorial.

Chopin, Henri. (1979) Poésie Sonore International. Paris: Jean-Michel Place.

Callado, Antonio. (1976). Reflexos do Baile. Rio de Janeiro: Paz e Terra.

Clüver, Claus. (2000). Concrete Poetry and the New Performance Arts:Intersemiotic, Intermedia, Intercultural. Em East of West. Cross-Cultura Performance and the Staging of Difference, organizado por Claire Sponsler e Xiaomei Chen, 33-61. London: Palgrave Macmillan.

Clüver, Claus. (1999). The Musikgedicht. Notes on an Ekphrastic Genre. Em Word and

Music Studies: Defining the Field, organizado por Walter Bernhart, Steven Paul Scher and Werner Wolf, 187-204. Amsterdam and Atlanta, GA: Editions Rodopi.

Clüver, Claus. (2002).Concrete Sound Poetry. Between Poetry and Music. Em Cultural Functions of Intermedial Exploration, organizado por Erik Hedling e Ulla-Britta Lagerroth, 163-178. Amsterdam, New York: Editions Rodopi, 2002.

Corona, Ricardo. (2002). Simbolista. Em Na virada do século, organizado por Cláudio Daniel e Frederico Barbosa, 269. São Paulo: Landy.

Feld, Steven. (2012). Sound and sentiment: Birds, weeping, poetics and song in Kaluli expression, 3rd edition, Duke University Press. 
Langer. Susanne K. (1953).Feeling and Form. New York: Charles Scribner's Sons.

Medeiros, Sérgio. (2003).Cage and Joyce. Em ABEI JOURNAL. The Brazilian Journal of Irish Studies. Interrelations. (2003) 5, 51-56.

Mello e Souza, Gilda. (1979). O tupi e o alaúde. Uma intepretação de Macunaíma. São Paulo: Duas Cidades.

Menezes, Philadelpho. (1992). Poesia Sonora: Poéticas Experimentais da Voz no Século XX. São Paulo: Ed. EDUC.

Oliveira, Solange Ribeiro de. (2002). Literatura e Música: Modulações Pós-Coloniais. São Paulo: Perspectiva.

Oliveira, Solange Ribeiro de. (2011). De Mendigos e Malandros: Chico Buarque, Bertolt Brecht, John Gay 2a edição. Curitiba: Editora CRV.

Oliveira, Solange Ribeiro de. (2006). Canção: Letra x Estrutura Musical. Aletria. Revista de Estudos de Literatura, vol. 14, 323-333.

Oliveira, Solange Ribeiro de. (2012). E a Música? Poesia Sonora ou Música Concreta? Em Perdida entre Signos: Literatura, Artes e Mídias, hoje, 187-197. Belo Horizonte: Faculdade de Letras da UFMG.

Ramos, Maria Luiza. (2000). Maíra: Leitura/Escritura. Em Literatura, Mito, Inconsciente, Cognição, 141-160. Belo Horizonte: Editora da UFMG, 2000.

Ripple, Gabrielle. (2015). Literature and Music: Theory. Em The Handbook of Intermediality. organizado por Gabrielle Ripple, 459-475. Berlin: De Gruyter.

Santiago, Silviano.(1986).A estrutura musical no romance: o caso de Érico Veríssimo. Em Anais do Simpósio de Literatura Comparada, 2, organizado por Júlio César Machado Pinto \& Eneida Maria de Souza, 164-165. Belo Horizonte: Editora da UFMG, 1986.

Scher, Steven Paul. (1968). Verbal Music in German Literature. New Haven: Yale University Press.

Scher, Steven Paul.(1970). Notes Toward a Theory of Verbal Music. Comparative Literature (22), 147-156.

Scher, Steven Paul. (1982) Literature and Music. Em Interrelations of Literature, organizado por Jean Pierre Barricelli \& Joseph Gibaldi, 225-250. New York: MLA.

Tatit, Luis. (1996). O Cancionista. Composição de Canções no Brasil São Paulo: Edusp.

Zumthor, Paul. (1992). Poesia do espaço. Novos territórios para uma nova oralidade. Em Poesia sonora: poéticas experimentais da voz no século XX. São Paulo: EDUC.

Wolf, Werner. (2015). Intermediality Revisited. Reflections on Word and Music Relations in the Context of a General Typology of Intermediality. Em A Handbook of Intermediality, organizado por Gabrielle Ripple, Berlin: DE Gruyter. 459-475.

Zumthor, Paul. (1998). Introdução à Poesia Oral. São Paulo: Ed. Hucitec / Educ. 


\section{Discografia}

CD Poesia sonora hoje - uma antologia internacional - LLS-002/A

Vários, P. Menezes (ed.), 1998.

CD- Strick Song of the Andoumboulou . Leitura, pelo poeta Nathaniel Mackey, de trechos do poema "Song of the Andoumboulou", com acompanhamento de percussão e flauta. MemphisSpoken Engine, 2005.

Data receção: 25/10/2019

Data aprovação: 13/03/2020 